Check for updates

Cite this: RSC Adv., 2020, 10, 28516

\title{
Controlling the oxidation state of molybdenum oxide nanoparticles prepared by ionic liquid/metal sputtering to enhance plasmon-induced charge separation $\dagger$
}

\author{
Kazutaka Akiyoshi, ${ }^{a}$ Tatsuya Kameyama, (D) a Takahisa Yamamoto, ${ }^{a}$ \\ Susumu Kuwabata, ${ }^{\mathrm{b}}$ Tetsu Tatsuma (D) ${ }^{\mathrm{C}}$ and Tsukasa Torimoto (D) *a
}

\begin{abstract}
Nanoparticles composed of molybdenum oxide, $\mathrm{MoO}_{x}$, were successfully prepared by room-temperature ionic liquid (RTIL)/metal sputtering followed by heat treatment. Hydroxyl groups in RTIL molecules retarded the coalescence between $\mathrm{MoO}_{x} \mathrm{NPs}$ during heat treatment at $473 \mathrm{~K}$ in air, while the oxidation state of Mo species in $\mathrm{MoO}_{x}$ nanoparticles (NPs) could be modified by changing the heat treatment time. An LSPR peak was observed at $840 \mathrm{~nm}$ in the near-IR region for $\mathrm{MoO}_{x} \mathrm{NPs}$ of $55 \mathrm{~nm}$ or larger in size that were annealed in a hydroxyl-functionalized RTIL. Photoexcitation of the LSPR peak of $\mathrm{MoO}_{x}$ NPs induced electron transfer

from NPs to ITO electrodes.
\end{abstract}

Received 12th June 2020

Accepted 14th July 2020

DOI: $10.1039 / \mathrm{dOra05165a}$

rsc.li/rsc-advances

\section{Introduction}

Light irradiation of plasmonic nanoparticles (NPs) can induce a collective oscillation of free carriers, so-called localized surface plasmon resonance (LSPR), that can lead to the generation of strong electromagnetic fields at the surfaces. ${ }^{1}$ When plasmonic NPs were combined with a semiconductor such as $\mathrm{TiO}_{2}$ or ZnO, plasmon-induced charge separation (PICS), ${ }^{2-5}$ by which electrons or holes moved from the NPs to the semiconductor, was observed. Recently, there have been some reports published on PICS from plasmonic NPs to metallic conductors such as graphene substrates ${ }^{6-9}$ and indium tin oxide (ITO) electrodes. ${ }^{10-15}$ This phenomenon has been intensively investigated for the development of photovoltaics, photocatalysts, and biosensors. ${ }^{2-5,16-18}$ So far, most research on PICS has been carried out with metal NPs showing intense LSPR peaks, such as Au and Ag.

Recently, much attention has been given to the development of novel plasmonic nanostructures with less expensive materials. Among the various materials for possible application, metal oxides have been promising because the position of LSPR peaks was reported to be easily controlled over a wide wavelength region from visible light to near-IR light by changing the

${ }^{a}$ Graduate School of Engineering, Nagoya University, Furo-cho, Chikusa-ku, Nagoya 464-8603, Japan. E-mail: torimoto@apchem.nagoya-u.ac.jp

${ }^{b}$ Graduate School of Engineering, Osaka University, 2-1 Yamada-oka, Suita, Osaka 565-0871, Japan

'Institute of Industrial Science, The University of Tokyo, 4-6-1 Komaba, Meguro-ku, Tokyo 153-8505, Japan

$\dagger$ Electronic supplementary information (ESI) available. See DOI: 10.1039/d0ra05165a composition. ${ }^{19-21}$ For example, several kinds of semiconductor/ metal oxide systems including $\mathrm{TiO}_{2} / \mathrm{MoO}_{3}{ }^{22}{ }^{2} \mathrm{TiO}_{2} / \mathrm{ITO},{ }^{23}$ and $\mathrm{SnO}_{2} / \mathrm{ITO}^{24}$ have been reported to exhibit PICS. However, the preparation methods have not yet been completely optimized. Furthermore, the efficiency of PICS has been low at a longer wavelength because the energy of absorbed photons seemed to be too low for photogenerated electrons to overcome the Schottky barrier height at the metal-semiconductor interface. , $^{42-29}$

On the other hand, room-temperature ionic liquids (RTILs) have been fascinating media to prepare nanostructured materials because the obtained structures were quite stable without the addition of any stabilizing agents..$^{30-39}$ We have reported strategies to prepare metal and alloy NPs by sputtering a metal onto RTILs under a reduced pressure, the RTIL/metal sputtering technique, with the use of unique features of RTILs such as extremely low vapor pressure and high thermal stability. ${ }^{40-42}$ This technique enabled clean preparation of plasmonic NPs such as $\mathrm{Au},{ }^{43} \mathrm{Ag},{ }^{44} \mathrm{Cu},{ }^{45} \mathrm{AgAu},{ }^{46}$ and $\mathrm{AuCu} \cdot{ }^{47}$ Furthermore, when transition metals with relatively negative redox potentials were sputter-deposited on RTILs, corresponding metal oxides, such as indium oxide, ${ }^{48}$ molybdenum oxide, and tungsten oxide, ${ }^{49}$ were formed via oxidation with $\mathrm{O}_{2}$ or $\mathrm{H}_{2} \mathrm{O}$ contained in the RTIL as an impurity. However, the optical properties of thus-obtained NPs have not been reported.

In this study, we controlled the oxidation state of molybdenum oxide NPs prepared by the RTIL/metal sputtering technique and we investigated their LSPR properties. Furthermore, their PICS behaviour was clarified by irradiating thus-obtained NPs immobilized on ITO electrodes. 


\section{Experimental}

\section{Preparation of molybdenum oxide NPs}

RTILs of 1-hydroxyethyl-3-methylimidazolium tetrafluoroborate $\left(\mathrm{HyEMI}_{-\mathrm{BF}}\right)$ and 1-ethyl-3-methylimidazolium tetrafluoroborate $\left(\mathrm{EMI}^{\left.-\mathrm{BF}_{4}\right)}\right.$ were dried at $373 \mathrm{~K}$ for $3 \mathrm{~h}$ with vigorous stirring under a vacuum condition before use. The contents of water were determined to be 560 ppm and 90 ppm for HyEMI-

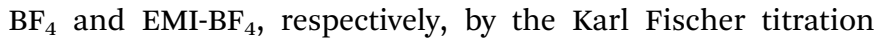
method (Kyoto Electronics Manufacturing, MKC-610). An RTIL $\left(0.60 \mathrm{~cm}^{3}\right)$ was spread on a glass plate $\left(10 \mathrm{~cm}^{2}\right)$ that was horizontally set in the sputter coater (Sanyu Electron Co. Ltd., SC701HMCII). The surface of the RTIL was located at a distance of $25 \mathrm{~mm}$ from the Mo target (99.99\% in purity). Sputter deposition of Mo on RTILs was carried out for $1 \mathrm{~h}$ with a discharge current of 10, 20,30, or $40 \mathrm{~mA}$ under argon pressure of 3.0 Pa. The as-sputter-deposited NPs were further oxidized to produce $\mathrm{MoO}_{x}$ NPs by annealing RTILs containing NPs at $473 \mathrm{~K}$ for various times, typically $30 \mathrm{~min}$, in air with relative humidity of $40-50 \%$.

Extinction spectra of NPs in RTILs were measured by a spectrophotometer (Agilent Technologies, Agilent 8453) in which a quartz cell with a light path length of $0.10 \mathrm{~mm}$ was used, and a blank solution for the measurements was an RTIL without metal sputtering. The concentration of Mo deposited in an RTIL was determined by X-ray fluorescence spectroscopy (Rigaku, EDXL300). Structural morphology of the NPs was observed by using a transmission electron microscope (TEM; HITACHI, H-7650) operated with an acceleration voltage at 100 $\mathrm{kV}$. A Cs-corrected HR-STEM (JEOL, ARM-200F) with an acceleration voltage of $200 \mathrm{kV}$ was used to acquire high-resolution TEM images. Samples for TEM observation were prepared by dipping a copper grid with amorphous carbon overlayers (Oken Shoji, \# 10-1012) into the RTIL containing NPs. The excess amount of RTIL was rinsed with acetonitrile followed by drying. $\mathrm{X}$-ray diffraction (XRD) patterns were measured with an X-ray diffractometer (Rigaku, SmartLab-3K) using $\mathrm{Cu} \mathrm{K} \alpha$ radiation. The samples for the XRD measurements were prepared by separating the NPs from RTILs. A large amount of acetonitrile was added to NP-containing RTILs. The resulting mixture was centrifuged, and the precipitates were set onto a lowbackground silicon sample holder.

\section{Photoelectrochemical measurements}

$\mathrm{MoO}_{x}$ NPs were isolated by centrifugation at $15000 \mathrm{rpm}$ for 5 min and washed with acetonitrile several times. The thusobtained NPs were finally dispersed in acetonitrile. The $\mathrm{MoO}_{x}$ NP dispersion was spread on an ITO substrate, followed by drying. The resulting electrode with NPs of $9.4 \times 10^{-6} \mathrm{~mol} \mathrm{~cm}^{-2}$ as Mo atoms was used as a working electrode for photoelectrochemical measurements, and an $\mathrm{Ag} / \mathrm{AgCl}$ electrode and a $\mathrm{Pt}$ wire were used as a reference electrode and a counter electrode, respectively. The $\mathrm{MoO}_{x}$ NP-immobilized ITO electrodes, ITO $/ \mathrm{MoO}_{x} \mathrm{NPs}$, were irradiated with a Xe lamp $(\lambda>350$

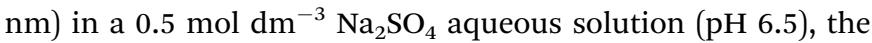
light intensity of which was $0.37 \mathrm{~W} \mathrm{~cm}^{-2}$. Action spectra of the photocurrent were obtained by passing the light of the Xe lamp through a monochromator (Jasco, CT-10), in which the incident photon-to-electron conversion efficiency (IPCE) was plotted as a function of the wavelength of irradiated monochromatic light.

\section{Results and discussion}

\section{Preparation of molybdenum oxide NPs showing LSPR}

We previously reported that sputter deposition of Mo on EMI$\mathrm{BF}_{4}$ produced NPs composed of molybdenum oxide with various Mo valences. ${ }^{49}$ However, their optical properties were not clarified. Thus, at first, we investigated the influence of the kind of RTILs used on the optical properties of deposited NPs.

The colour of the Mo-deposited HyEMI-BF H $_{4}$ solution was remarkably changed by heat treatment from yellow brown at $0 \mathrm{~min}$, dark brown at $30 \mathrm{~min}$, to light brown at $120 \mathrm{~min}$. As shown in Fig. 1a, the NPs in HyEMI-BF 4 solution exhibited a structureless spectrum just after Mo sputter deposition, but the following heat treatment at $473 \mathrm{~K}$ resulted in the development of a new peak at $c a .840 \mathrm{~nm}$. The peak intensity increased with the elapse of heating time to $30 \mathrm{~min}$ and then decreased with further heating. Since the LSPR peak of chemically synthesized oxygen-deficient $\mathrm{MoO}_{3}$ NPs was reported to be located in the wavelength range of $600-1000 \mathrm{~nm}^{50-53}$ the observed peak at $c a .840 \mathrm{~nm}$ was assignable to the LSPR peak of molybdenum oxide NPs. Furthermore, heating of NPs in

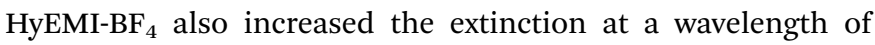
$700 \mathrm{~nm}$ or shorter.
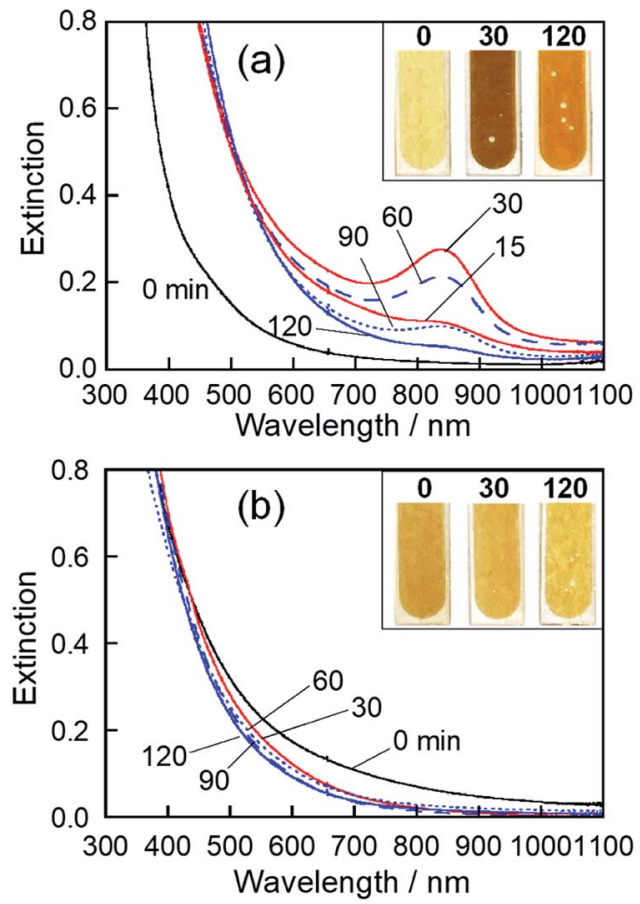

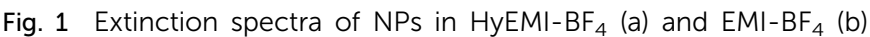
prepared by Mo sputtering (discharge current of $30 \mathrm{~mA}$ ) and their changes with heating at $473 \mathrm{~K}$ for various times in air. Photographs of the solutions with heating times of 0,30 , and $120 \mathrm{~min}$ are shown in the insets of the corresponding panels. 
$\mathrm{O} 1 \mathrm{~s}$ XPS spectra (Fig. $\mathrm{S} 1 \dagger$ ) revealed the presence of $\mathrm{Mo}-\mathrm{O}^{2-}$, Mo- $\mathrm{O}^{-}$and $\mathrm{Mo}-\mathrm{OH}$ species as well as adsorbed $\mathrm{H}_{2} \mathrm{O}$ on the surface $\left(\mathrm{Mo}-\mathrm{H}_{2} \mathrm{O}\right)$ in deposited NPs, regardless of the heat treatment. Fig. 2 shows the Mo 3d XPS spectra of NPs deposited

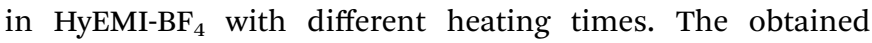
signals were successfully deconvoluted with Mo $3 \mathrm{~d}_{5 / 2}$ and $3 \mathrm{~d}_{3 / 2}$ of $230.8 \mathrm{eV}$ and $234.1 \mathrm{eV}$ for Mo(IV), $231.5 \mathrm{eV}$ and $234.6 \mathrm{eV}$ for $\mathrm{Mo}(\mathrm{v})$, and 232.7 and $235.8 \mathrm{eV}$ for $\mathrm{Mo}(\mathrm{vI})$, respectively. ${ }^{54} \mathrm{We}$ could obtain fractions of Mo species with different oxidation states from XPS signals, as shown in Table S1. $\dagger$ The fraction of Mo(vI) was increased from $25.7 \%$ to $68.3 \%$ in the total Mo species with heat treatment from 0 to $120 \mathrm{~min}$. No signals assignable to those at 228.3 and $231.5 \mathrm{eV}$ for $3 \mathrm{~d}_{5 / 2}$ and $3 \mathrm{~d}_{3 / 2}$, respectively, of $\operatorname{Mo}(0)^{54}$ were detected. These results indicated that the metallic Mo species deposited were immediately oxidized by oxygen molecules in air and/or $\mathrm{H}_{2} \mathrm{O}$ molecules contained in the RTIL as an impurity and then NPs of molybdenum oxides, $\mathrm{MoO}_{x}$, were formed in $\mathrm{HyEMI}_{\mathrm{BF}}$. Furthermore, we estimated the compositions of thus-obtained $\mathrm{MoO}_{x}$ NPs
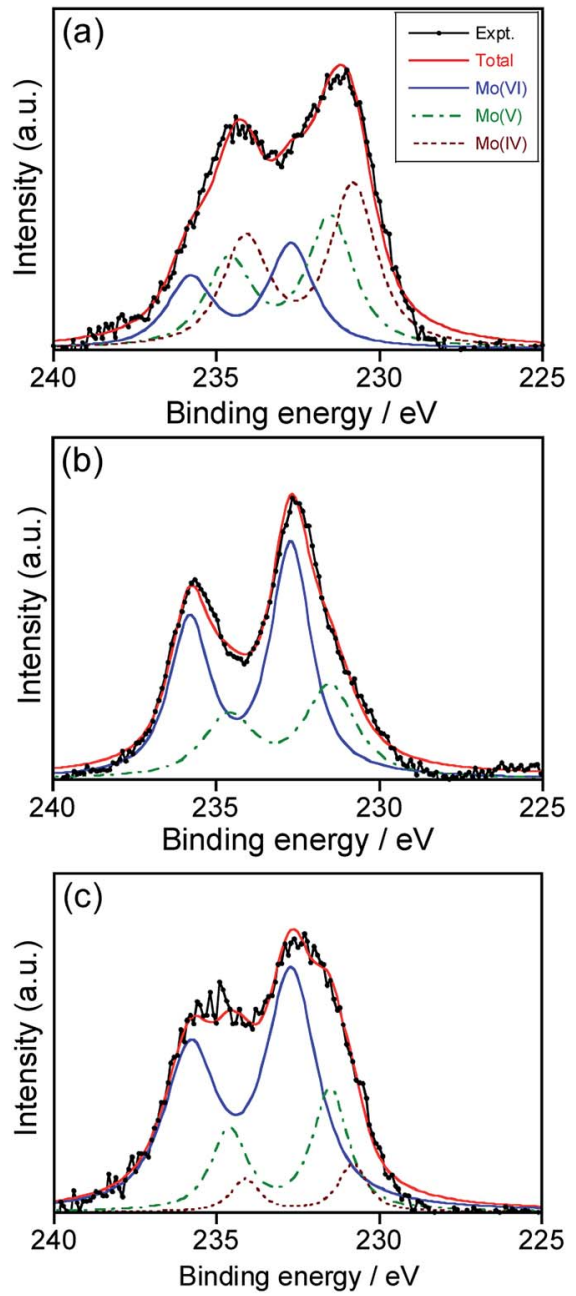

Fig. 2 XPS spectra for Mo $3 d$ levels of as-deposited $\mathrm{MoO}_{x} \mathrm{NPs}$ in

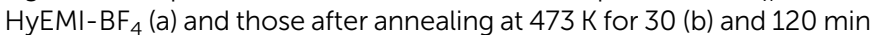
(c). The Mo sputtering was carried out with a discharge current of 30 $\mathrm{mA}$. heat-treated for 0,30 and $120 \mathrm{~min}$ to be $x=1.69,2.29$, and 3.09, respectively, from XPS signals of Mo and O.

The colour of $\mathrm{EMI}^{-\mathrm{BF}_{4}}$ sputter-deposited with Mo was slightly changed from brown to yellow-brown by heat treatment. Fig. 1b shows extinction spectra of as-deposited $\mathrm{MoO}_{x} \mathrm{NPs}$ in

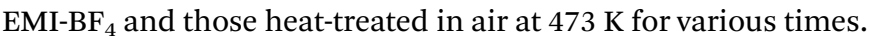
A structureless spectrum was observed for as-deposited NPs in

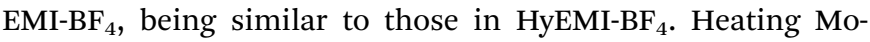

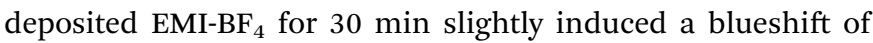
extinction spectra to the onset wavelength around $800 \mathrm{~nm}$ without showing an LSPR peak at around 800-900 nm, and further heat treatment up to 120 min scarcely changed the extinction spectra. XPS spectra of $\mathrm{MoO}_{x}$ NPs deposited in EMI$\mathrm{BF}_{4}$ (Fig. S2 $\dagger$ ) revealed that $\mathrm{MoO}_{x}$ NPs were composed of $\mathrm{Mo}(\mathrm{Iv})$, $\mathrm{Mo}(\mathrm{v})$, and $\mathrm{Mo}(\mathrm{vI})$ species, in which the fraction of $\mathrm{Mo}(\mathrm{VI})$ was roughly constant at $c a .20-27 \%$ regardless of the heating (Table $\mathrm{S} 1 \dagger)$, being different from the case of the NPs in $\mathrm{HyEMI}_{-} \mathrm{BF}_{4}$. The compositions of $\mathrm{MoO}_{x}$ NPs deposited in $\mathrm{EMI}^{-\mathrm{BF}_{4}}$ were also determined from XPS signals to be $x=1.17,1.61$ and 2.60 for samples heat-treated for 0,30 and $120 \mathrm{~min}$, respectively. It should be noted that each $x$ value for $\mathrm{MoO}_{x} \mathrm{NPs}_{\text {in }} \mathrm{EMI}^{-\mathrm{BF}_{4}}$ was smaller than the aforementioned value of corresponding NPs in HyEMI-BF 4 , indicating the NPs in EMI-BF ${ }_{4}$ are less susceptible to oxidation.

As already reported in the literature, NPs consisting of metal oxide semiconductors with an oxygen-deficient composition, such as $\mathrm{WO}_{3-y}$ and $\mathrm{MoO}_{3-y}$, can absorb light through three different electronic excitation modes: (i) interband transition, that is, transition from the valence band (VB) to the conduction band (CB), (ii) transition from the VB to oxygen-deficient states formed by metal species of different valences, such as $\operatorname{Mo}(\mathrm{v})$, and (iii) polaron-induced LSPR. ${ }^{55-58}$ In such metal oxide semiconductors, it was reported that the optical response was extended to a longer wavelength range than that expected from the intrinsic energy gap, ${ }^{59}$ because oxygen vacancies formed defect states between the CB and the Fermi level $\left(E_{\mathrm{F}}\right)$, narrowing their optical band gap. Considering the $\mathrm{MoO}_{3}$ energy gap of approximately $3 \mathrm{eV}$, corresponding to $413 \mathrm{~nm},{ }^{55,60}$ the extinction in the wavelength region of $700 \mathrm{~nm}$ or shorter in Fig. 1 seemed to be due to transition from the VB to oxygen vacancy states formed by Mo(Iv) and Mo(v) species.

The appearance of the LSPR peak of $\mathrm{MoO}_{x} \mathrm{NPs}_{\text {in }} \mathrm{HyEMI}-\mathrm{BF}_{4}$ can be understood by considering two factors, the amount of oxygen vacancies and particle size. As mentioned above for the results shown in Fig. 2 and Table $\mathrm{S} 1, \dagger$ heat treatment of $\mathrm{MoO}_{x}$

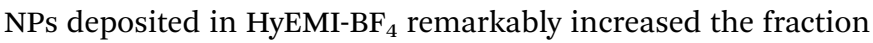
of $\mathrm{Mo}(\mathrm{vI})$ in the total Mo species with the elapse of heating time. When NPs in HyEMI-BF ${ }_{4}$ were heated for $30 \mathrm{~min}$ at $473 \mathrm{~K}$, the Mo(Iv) species disappeared. For such NPs, the chemical formula was calculated to be $\mathrm{MoO}_{2.29}$, the amount of oxygen vacancies of which was smaller than that of as-sputter-deposited NPs in EMI$\mathrm{BF}_{4}, \mathrm{MoO}_{1.61}$. These results suggested that an appropriate amount of oxygen vacancies was formed with heat treatment for $30 \mathrm{~min}$ and could then produce free electrons in the $\mathrm{MoO}_{3}$ structure for the LSPR peak shown in Fig. 1a to emerge. However, the LSPR peak almost disappeared with further heat treatment, and the chemical formula of NPs changed from 
$\mathrm{MoO}_{2.29}$ to $\mathrm{MoO}_{3.09}$ with prolonged heating from 30 to $120 \mathrm{~min}$ (Table $\mathrm{S} 1 \dagger$ ). The decrease in the amount of oxygen vacancies resulted in a reduction in the number of free electrons. ${ }^{\mathbf{6 1 , 6 2}}$ Another reason for the decrease in LSPR peak intensity was the change in size of $\mathrm{MoO}_{x}$ NPs with heating. It is well known that the position of LSPR peaks is very sensitive to the size of plasmonic nanoparticles, regardless of metals or metal oxides, being red-shifted with an increase in particle size. ${ }^{\mathbf{6 3 , 6 4}}$

Fig. 3 shows TEM images of $\mathrm{MoO}_{x}$ NPs deposited in HyEMI$\mathrm{BF}_{4}$ and EMI-BF . As-deposited NPs in HyEMI-BF $_{4}$ were spherical particles with sizes of $6.8 \pm 4.9 \mathrm{~nm}$, which were larger than

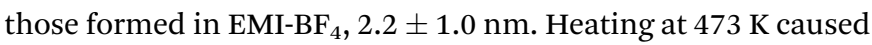
significant coalescence between NPs. After heating for $30 \mathrm{~min}$, the NPs in HyEMI-BF 4 were $c a .65 \mathrm{~nm}$ in size, being much

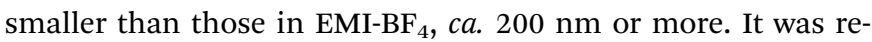
ported previously that thermal oxidation of In metal in $\mathrm{EMI}^{-\mathrm{BF}_{4}}$ at $523 \mathrm{~K}$ produced largely aggregated NPs but that similar heat treatment in HyEMI-BF 4 gave uniformly dispersed $\operatorname{In}_{2} \mathrm{O}_{3}$ NPs of $28 \mathrm{~nm}$ in diameter, indicating that hydroxyl groups in cationic species of RTILs were strongly adsorbed on the metal oxide surface to improve the dispersibility of NPs in the solutions. ${ }^{65}$ Thus, the results of the present study suggested that hydroxyl groups in $\mathrm{HyEMI}-\mathrm{BF}_{4}$ molecules could be adsorbed on the $\mathrm{MoO}_{x}$ surface to retard the coalescence between NPs. The concentration of water in RTILs was also reported to significantly affect the size of $\operatorname{In}_{2} \mathrm{O}_{3}$ NPs formed, and the larger NPs were produced
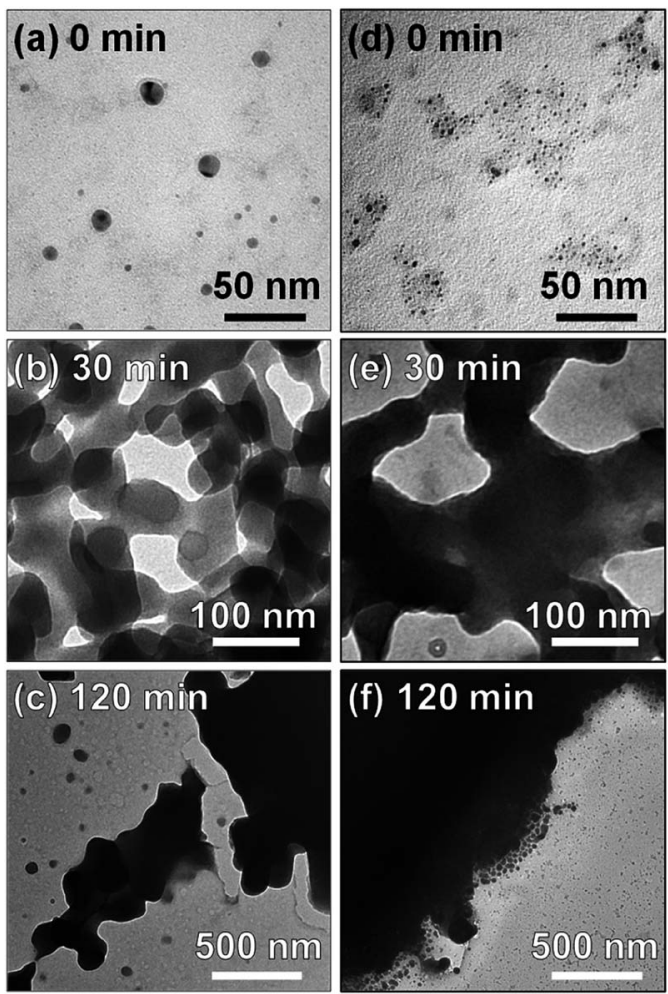

Fig. 3 TEM images of as-deposited $\operatorname{MoO}_{x}$ NPs (a and d) and those after annealing at $473 \mathrm{~K}$ for 30 ( $\mathrm{b}$ and e) and $120 \mathrm{~min}$ ( $\mathrm{c}$ and f). The RTILs

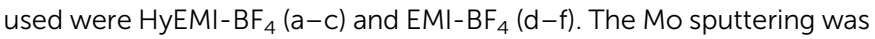
carried out with a discharge current of $30 \mathrm{~mA}$. with an increase in the water concentration in RTILs. ${ }^{65}$ In the

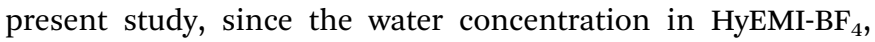

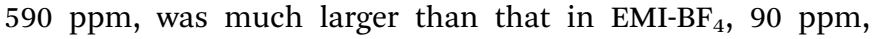
a higher growth rate of $\mathrm{MoO}_{x}$ was expected in HyEMI-BF 4 , resulting in a larger number of NPs with a smaller average size. In both kinds of RTIL, the heated NPs were connected with each other to form a network structure. Furthermore, prolonged heat treatment for $120 \mathrm{~min}$ remarkably enlarged the size of NPs to several micrometres. Thus, it was thought that the formation of larger $\mathrm{MoO}_{x} \mathrm{NPs},>200 \mathrm{~nm}$, in EMI-BF 4 prevented the appearance of the LSPR peak.

Fig. 4 shows high-resolution TEM images of $\mathrm{MoO}_{x}$ NPs formed in $\mathrm{HyEMI}_{-} \mathrm{BF}_{4}$. Lattice fringes with interplanar spacings of 0.26 and $0.33 \mathrm{~nm}$ were observed for as-deposited NPs in $\mathrm{HyEMI}_{-\mathrm{BF}_{4}}$ and those heat-treated at $473 \mathrm{~K}$ for $30 \mathrm{~min}$, being assignable to (111) and (021) planes of orthorhombic $\mathrm{MoO}_{3}$ crystal structure, respectively. As shown in Fig. 4a, most asdeposited NPs showed lattice fringes only in a partial area of the particle. On the other hand, large particles obtained after annealing were composed of small NPs of $c a$. 1.5-6 $\mathrm{nm}$ in size as shown in Fig. 4b and many grain boundaries could be recognized inside the particle, indicating that each particle was polycrystalline. It should be noted that as-sputter-deposited NPs showed no characteristic diffraction peaks in the XRD patterns (Fig. S3 $\dagger$ ), though the NPs after heating at $473 \mathrm{~K}$ for $30 \mathrm{~min}$
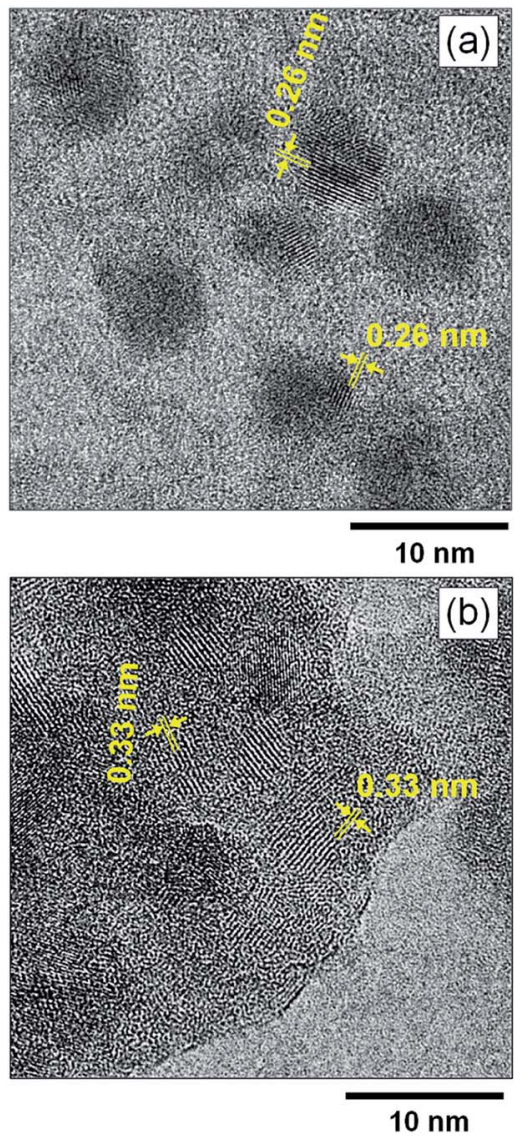

Fig. 4 High-resolution TEM images of (a) as-deposited $\mathrm{MoO}_{x}$ NPs in

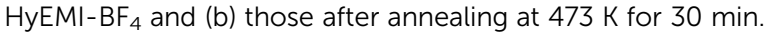


exhibited a broad diffraction peak at $\mathrm{ca} .24-27^{\circ}$, being assignable to orthorhombic $\mathrm{MoO}_{3}$ structure. These results suggested that the as-deposited NPs were composed of amorphous phase containing a very small amount of orthorhombic $\mathrm{MoO}_{3}$ crystal phase that could not be detected by XRD analysis but that the heat treatment increased both the fraction of orthorhombic crystal phase in NPs and their crystallinity as well as the size of coalesced NPs.

The discharge current used for the RTIL/metal sputtering technique is an important parameter for controlling the concentrations of metal species sputter-deposited in RTILs. For example, the concentrations of Au and $\mathrm{Ag}$ NPs deposited, as well as the size of NPs deposited, were increased with an increase in the discharge current. ${ }^{6,67}$ We investigated the influence of discharge current on the LSPR peak of the resulting $\mathrm{MoO}_{x} \mathrm{NPs}_{\text {. }}$ As-deposited NPs in HyEMI-BF H $_{4}$ exhibited a larger extinction at a wavelength shorter than $800 \mathrm{~nm}$ in individual spectra but did not show any LSPR peaks (Fig. S4 $\dagger$ ). The extinction at a constant wavelength was enlarged with an increase in the discharge current. The size of as-sputter-deposited $\mathrm{MoO}_{x}$ NPs increased from $2.0 \mathrm{~nm}$ to $17 \mathrm{~nm}$ with an increase in the discharge current from $10 \mathrm{~mA}$ to $40 \mathrm{~mA}$ (not shown). The concentration of Mo atoms deposited in $\mathrm{HyEMI}-\mathrm{BF}_{4}$ linearly increased with increase in the discharge current (inset of Fig. 5b). On the other hand, the LSPR peak appeared at $c a .840 \mathrm{~nm}$ as shown in Fig. 5a when the NPs sputter-deposited with a discharge current of $20 \mathrm{~mA}$ or
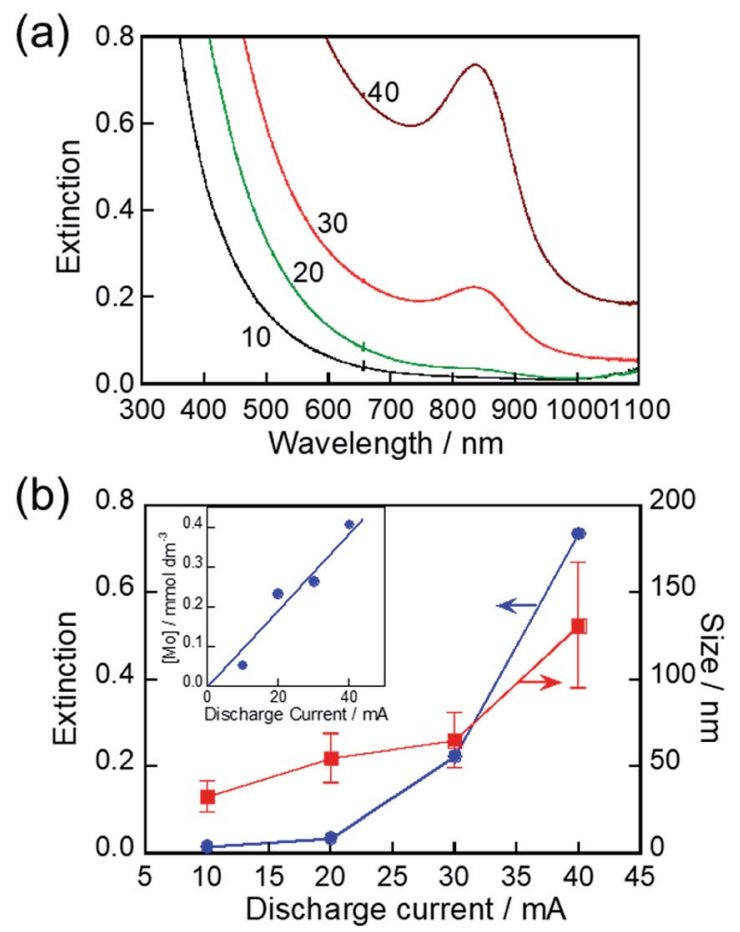

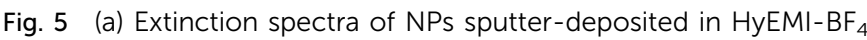
with various discharge currents after heating at $473 \mathrm{~K}$ for $30 \mathrm{~min}$. Discharge currents in units of $\mathrm{mA}$ are shown in the panel. (b) Plots of extinction at $840 \mathrm{~nm}$ in panel a and size of heat-treated $\mathrm{MoO}_{x} \mathrm{NPs}$ in the solution as a function of discharge current (inset). Relationship

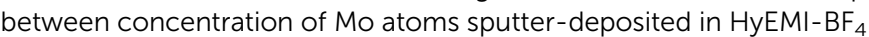
and discharge current. larger were heat-treated at $473 \mathrm{~K}$ for $30 \mathrm{~min}$ in air. Heating asdeposited NPs enlarged the particle size, accompanied by interconnection between the resulting NPs to form a network structure (Fig. S5 $\dagger$ ). Fig. 5b shows the size of heat-treated $\mathrm{MoO}_{x}$ NPs as a function of discharge current. With an increase in the discharge current from $10 \mathrm{~mA}$ to $40 \mathrm{~mA}$, the average size of resulting NPs increased from $32 \mathrm{~nm}$ to $131 \mathrm{~nm}$, indicating that the degree of coalescence increased with an increase in the Mo concentration in the solution. As clearly shown in Fig. 5b, an LSPR peak appeared at $840 \mathrm{~nm}$ for $\mathrm{MoO}_{x}$ NPs with sizes of $55 \mathrm{~nm}$ or larger. It was reported that spherical Au NPs smaller than ca. $2 \mathrm{~nm}$ did not show a clear LSPR peak. ${ }^{68-70}$ Thus, the results suggest that the minimum size for showing an LSPR peak is $c a .55 \mathrm{~nm}$ for $\mathrm{MoO}_{x}$ NPs prepared in the present study.

\section{Plasmon-induced charge transfer from $\mathrm{MoO}_{x}$ NPs}

As mentioned above, we successfully prepared $\mathrm{MoO}_{x}$ NPs with or without showing an LSPR peak in the near-IR region by changing the kind of RTIL used for sputter deposition. These NPs seem to be suitable for investigating the photoelectrochemical response of $\mathrm{MoO}_{x}$ NPs with LSPR excitation in the near-IR wavelength region. Fig. 6a shows photocurrentpotential curves of ITO/MoO $x$ NPs, where $\mathrm{MoO}_{x}$ NPs were prepared by Mo sputter deposition in HyEMI-BF 4 and EMI-BF 4 followed by heat treatment at $473 \mathrm{~K}$ for $30 \mathrm{~min}$ in air. Anodic photocurrents were observed at a more positive potential than
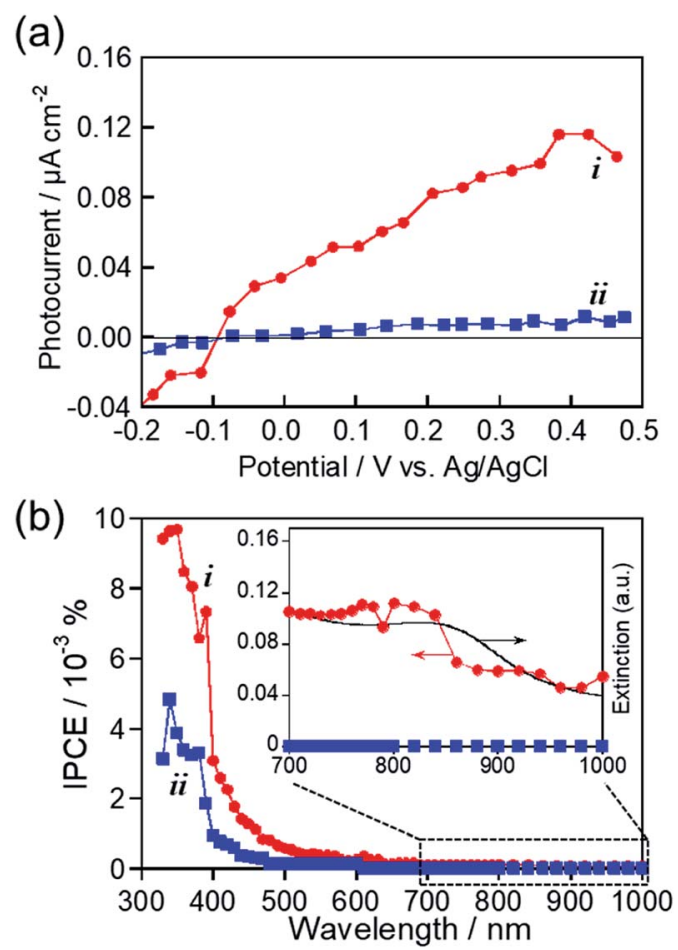

Fig. 6 (a) Photocurrent-potential curves for $1 \mathrm{TO} / \mathrm{MoO}_{x} \mathrm{NP}$ electrodes. The $\mathrm{MoO}_{x} \mathrm{NPs}$ were prepared by Mo sputter deposition in

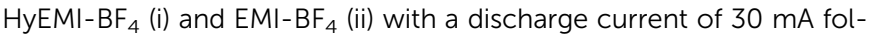
lowed by heat treatment at $473 \mathrm{~K}$ for $30 \mathrm{~min}$ in air. (b) Action spectra of anodic photocurrents in panel a under potential application at $0.5 \mathrm{~V}$ vs. $\mathrm{Ag} / \mathrm{AgCl}$. 
$-0.1 \mathrm{~V} v s . \mathrm{Ag} / \mathrm{AgCl}$ in both cases, the magnitude being increased with a positive shift of the applied potential. These results indicated that the obtained $\mathrm{MoO}_{x}$ NPs exhibited a photoresponse similar to that of an n-type semiconductor photoelectrode, as reported previously. ${ }^{55,71}$ Furthermore, it should be noted that the NPs prepared in $\mathrm{EMI}^{-\mathrm{BF}_{4}}$ exhibited a much lower

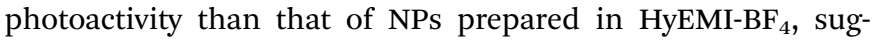
gesting the presence of a larger amount of carrier recombination sites or trap sites in NPs.

Photocurrent action spectra were measured under potential application at $0.5 \mathrm{~V}$ vs. Ag/AgCl. As shown in Fig. 6b, photoexcitation of the interband transition of $\mathrm{MoO}_{3}$ with light of wavelengths shorter than $\mathrm{ca}$. $400 \mathrm{~nm}$ produced a predominant fraction of anodic photocurrent in both cases, though the NPs prepared in $\mathrm{HyEMI}^{-\mathrm{BF}_{4}}$ exhibited higher IPCE values than those

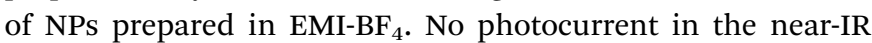
region was observed for NPs in $\mathrm{EMI}^{-\mathrm{BF}_{4}}$. However, the peak assignable to LSPR of $\mathrm{MoO}_{x}$ NPs at around $840 \mathrm{~nm}$ was observed

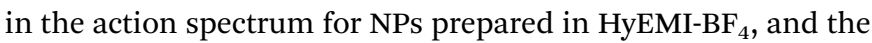
spectrum outline agreed well with that of their extinction spectrum. This suggested that PICS was observed for ITO/MoO NPs: the LSPR excitation produced electrons excited in the conduction band of $\mathrm{MoO}_{x} \mathrm{NPs}$, which were injected into the ITO electrode. ${ }^{15}$ It should be noted that the IPCEs obtained with excitation of the LSPR peak of $\mathrm{MoO}_{x}$ NPs were considerably lower than those with photoexcitation of the interband transition at $c a .400 \mathrm{~nm}$ or shorter. It was reported that PICS systems with photoexcitation of near-IR light, such as $\mathrm{ITO} / \mathrm{TiO}_{2} / \mathrm{ITO}$ $\mathrm{NPs}^{23}$ and ITO/Au NPs/TiO ${ }_{2},{ }^{29}$ exhibited relatively low IPCEs of similar order of magnitude to those shown in Fig. 6b. The low IPCEs obtained in the near-IR region were probably because the energy of excited electrons, generated by LSPR photoexcitation, was too low to overcome the Schottky barrier height at the metal-semiconductor interface and/or because back-electron transfer easily occurred from conducting electrodes to plasmonic NPs. Thus, we concluded that the RTIL/metal sputtering technique provides a useful strategy for preparing plasmonic $\mathrm{MoO}_{x}$ NPs and that LSPR excitation enables plasmon-induced charge transfer from thus-obtained NPs to ITO electrodes.

\section{Conclusions}

We successfully prepared $\mathrm{MoO}_{x}$ NPs showing an LSPR peak in the near-IR region by RTIL/metal sputtering followed by heat treatment. The degree of coalescence between NPs was dependent on the kind of RTIL used, and hydroxyl groups in RTIL molecules could be adsorbed on the $\mathrm{MoO}_{x}$ surface to stabilize NPs in the RTIL. Heat treatment of as-deposited $\mathrm{MoO}_{x}$ NPs enabled control of the oxidation state of Mo species in NPs. The LSPR peak was observed in the near-IR region for $\mathrm{MoO}_{x} \mathrm{NPs}$ of $55 \mathrm{~nm}$ or larger in size that were prepared in a hydroxylfunctionalized RTIL. Photoexcitation of the LSPR peak of $\mathrm{MoO}_{x}$ NPs induced electron transfer from NPs to ITO electrodes. The photoresponsivity of $\mathrm{MoO}_{x}$ in the near-IR region will be useful for developing novel plasmonic devices such as photocatalysts and solar cells. ${ }^{72}$ Our RTIL/metal sputtering technique coupled with heat treatment will provide a useful strategy for controlling the oxidation states of metal oxide particles for plasmonic nanostructures.

\section{Conflicts of interest}

There are no conflicts to declare.

\section{Acknowledgements}

This work was financially supported by JSPS KAKENHI grant numbers JP16H06507 in Scientific Research on Innovative Areas "Nano-Material Optical-Manipulation,” JP18H03927, and JP18K19128.

\section{References}

1 H. Raether, Surface Plasmons on Smooth and Rough Surfaces and on Gratings, Springer-Verlag, Berlin, 1988.

2 Y. Tian and T. Tatsuma, J. Am. Chem. Soc., 2005, 127, 7632.

3 C. Clavero, Nat. Photonics, 2014, 8, 95.

4 M. L. Brongersma, N. J. Halas and P. Nordlander, Nat. Nanotechnol., 2015, 10, 25.

5 T. Tatsuma, H. Nishi and T. Ishida, Chem. Sci., 2017, 8, 3325.

6 D. Kumar, A. Lee, T. Lee, M. Lim and D.-K. Lim, Nano Lett., 2016, 16, 1760.

7 W. Lin, Y. Cao, P. Wang and M. Sun, Langmuir, 2017, 33, 12102.

8 E. Cao, X. Guo, L. Zhang, Y. Shi, W. Lin, X. Liu, Y. Fang, L. Zhou, Y. Sun, Y. Song, W. Liang and M. Sun, Adv. Mater. Interfaces, 2017, 4, 1700869.

9 W. Lin, E. Cao, L. Zhang, X. Xu, Y. Song, W. Liang and M. Sun, Nanoscale, 2018, 10, 5482.

10 L. B. Lowe, S. H. Brewer, S. Krämer, R. R. Fuierer, G. Qian, C. O. Agbasi-Porter, S. Moses, S. Franzen and D. L. Feldheim, J. Am. Chem. Soc., 2003, 125, 14258.

11 K. Kawahara, K. Suzuki, Y. Ohko and T. Tatsuma, Phys. Chem. Chem. Phys., 2005, 7, 3851.

12 A. Al-Zubeidi, B. S. Hoener, S. S. E. Collins, W. Wang, S. R. Kirchner, S. A. H. Jebeli, A. Joplin, W.-S. Chang, S. Link and C. F. Landes, Nano Lett., 2019, 19, 1301.

13 E. Pensa, J. Gargiulo, A. Lauri, S. Schlücker, E. Cortés and S. A. Maier, Nano Lett., 2019, 19, 1867.

14 H. Nishi and T. Tatsuma, Nanoscale, 2019, 11, 19455.

15 T. Tatsuma and H. Nishi, Nanoscale Horiz., 2020, 5, 597.

16 A. Furube and S. Hashimoto, NPG Asia Mater., 2017, 9, e454.

17 K. Ueno, T. Oshikiri, Q. Sun, X. Shi and H. Misawa, Chem. Rev., 2018, 118, 2955.

18 N. Wu, Nanoscale, 2018, 10, 2679.

19 J. M. Luther, P. K. Jain, T. Ewers and A. P. Alivisatos, Nat. Mater., 2011, 10, 361.

20 S. D. Lounis, E. L. Runnerstrom, A. Llordés and D. J. Milliron, J. Phys. Chem. Lett., 2014, 5, 1564.

21 A. Agrawal, S. H. Cho, O. Zandi, S. Ghosh, R. W. Johns and D. J. Milliron, Chem. Rev., 2018, 118, 3121.

22 S. H. Lee, H. Nishi and T. Tatsuma, Nanoscale, 2018, 10, 2841. 
23 S. H. Lee, H. Nishi and T. Tatsuma, Phys. Chem. Chem. Phys., 2019, 21, 5674.

24 M. Sakamoto, T. Kawawaki, M. Kimura, T. Yoshinaga, J. J. M. Vequizo, H. Matsunaga, C. S. K. Ranasinghe, A. Yamakata, H. Matsuzaki, A. Furube and T. Teranishi, Nat. Commun., 2019, 10, 406.

25 Y. Nishijima, K. Ueno, Y. Kotake, K. Murakoshi, H. Inoue and H. Misawa, J. Phys. Chem. Lett., 2012, 3, 1248.

26 A. O. Govorov, H. Zhang and Y. K. Gun'ko, J. Phys. Chem. C, 2013, 117, 16616.

27 C. Ng, J. J. Cadusch, S. Dligatch, A. Roberts, T. J. Davis, P. Mulvaney and D. E. Gomez, ACS Nano, 2016, 10, 4704.

28 H. Nishi and T. Tatsuma, J. Phys. Chem. C, 2018, 122, 2330.

29 K. Akiyoshi and T. Tatsuma, Photochem. Photobiol. Sci., 2019, 18, 1727.

30 E. F. Borra, O. Seddiki, R. Angel, D. Eisenstein, P. Hickson, K. R. Seddon and S. P. Worden, Nature, 2007, 447, 979.

31 J. Dupont and J. D. Scholten, Chem. Soc. Rev., 2010, 39, 1780. 32 H. Wender, P. Migowski, A. F. Feil, S. R. Teixeira and J. Dupont, Coord. Chem. Rev., 2013, 257, 2468.

33 M. Armand, F. Endres, D. R. MacFarlane, H. Ohno and B. Scrosati, Nat. Mater., 2009, 8, 621.

34 S. Wegner and C. Janiak, Top. Curr. Chem., 2017, 375, 65.

35 Y. Hatakeyama, S. Takahashi and K. Nishikawa, J. Phys. Chem. C, 2010, 114, 11098.

36 Z. He and P. Alexandridis, Phys. Chem. Chem. Phys., 2015, 17, 18238.

37 H. Konnerth and M. H. G. Prechtl, Green Chem., 2017, 19, 2762-2767.

38 C. Verma, E. E. Ebenso and M. A. Quraishi, J. Mol. Liq., 2019, 276, 826.

39 M. Meischein, M. Fork and A. Ludwig, Nanomaterials, 2020, 10, 525 .

40 T. Torimoto, K. Okazaki, T. Kiyama, K. Hirahara, N. Tanaka and S. Kuwabata, Appl. Phys. Lett., 2006, 89, 243117.

41 T. Torimoto, T. Tsuda, K. Okazaki and S. Kuwabata, Adv. Mater., 2010, 22, 1196.

42 S. Kuwabata, T. Tsuda and T. Torimoto, J. Phys. Chem. Lett., 2010, 1, 3177.

43 E. Vanecht, K. Binnemans, J. W. Seo, L. Stappers and J. Fransaer, Phys. Chem. Chem. Phys., 2011, 13, 13565.

44 S. C. Hamm, R. Shankaran, V. Korampally, S. Bok, S. Praharaj, G. A. Baker, J. D. Robertson, B. D. Lee, S. Sengupta, K. Gangopadhyay and S. Gangopadhyay, ACS Appl. Mater. Interfaces, 2012, 4, 178.

45 K. Richter, A. Birkner and A.-V. Mudring, Angew. Chem., Int. Ed., 2010, 49, 2431.

46 K. Okazaki, T. Kiyama, K. Hirahara, N. Tanaka, S. Kuwabata and T. Torimoto, Chem. Commun., 2008, 691.

47 D. König, K. Richter, A. Siegel, A.-V. Mudring and A. Ludwig, Adv. Funct. Mater., 2014, 24, 2049.

48 T. Suzuki, K. Okazaki, S. Suzuki, T. Shibayama, S. Kuwabata and T. Torimoto, Chem. Mater., 2010, 22, 5209.

49 T. Suzuki, S. Suzuki, Y. Tomita, K. Okazaki, T. Shibayama, S. Kuwabata and T. Torimoto, Chem. Lett., 2010, 39, 1072.
$50 \mathrm{H}$. Cheng, T. Kamegawa, K. Mori and H. Yamashita, Angew. Chem., Int. Ed., 2014, 53, 2910.

51 J. Shi, Y. Kuwahara, M. Wen, M. Navlani-Garcia, K. Mori, T. An and H. Yamashita, Chem.-Asian J., 2016, 11, 2377.

52 X. Tan, L. Wang, C. Cheng, X. Yan, B. Shen and J. Zhang, Chem. Commun., 2016, 52, 2893.

53 S. H. Lee, H. Nishi and T. Tatsuma, Chem. Commun., 2017, 53, 12680.

54 Z. Song, T. Cai, Z. Chang, G. Liu, J. A. Rodriguez and J. Hrbek, J. Am. Chem. Soc., 2003, 125, 8059.

55 I. A. de Castro, R. S. Datta, J. Z. Ou, A. Castellanos-Gomez, S. Sriram, T. Daeneke and K. Kalantar-zadeh, Adv. Mater., 2017, 29, 1701619.

56 Z. Hai, Z. Wei, C. Xue, H. Xud and F. Verpoort, J. Mater. Chem. C, 2019, 7, 12968.

57 S. S. Kalanur, I.-H. Yoo, I.-S. Cho and H. Seo, Electrochim. Acta, 2019, 296, 517.

58 H. Quan, Y. Gao and W. Wang, Inorg. Chem. Front., 2020, 7, 817.

59 Y. Wang, J. Cai, M. Wu, J. Chen, W. Zhao, Y. Tian, T. Ding, J. Zhang, Z. Jiang and X. Li, Appl. Catal., B, 2018, 239, 398.

60 S. Balendhran, S. Walia, H. Nili, J. Z. Ou, S. Zhuiykov, R. B. Kaner, S. Sriram, M. Bhaskaran and K. Kalantarzadeh, Adv. Funct. Mater., 2013, 23, 3952.

61 M. M. Alsaif, M. R. Field, T. Daeneke, A. F. Chrimes, W. Zhang, B. J. Carey, K. J. Berean, S. Walia, J. van Embden, B. Zhang, K. Latham, K. Kalantar-Zadeh and J. Z. Ou, ACS Appl. Mater. Interfaces, 2016, 8, 3482.

62 G. Prusty, J. T. Lee, S. Seifert, B. B. Muhoberac and R. Sardar, J. Am. Chem. Soc., 2020, 142, 5938.

63 P. N. Njoki, I.-I. S. Lim, D. Mott, H.-Y. Park, B. Khan, S. Mishra, R. Sujakumar, J. Luo and C.-J. Zhong, J. Phys. Chem. C, 2007, 111, 14664.

64 K. Ma, N. Zhou, M. Yuan, D. Li and D. Yang, Nanoscale Res. Lett., 2014, 9, 547.

65 D. Sugioka, T. Kameyama, T. Yamamoto, S. Kuwabata and T. Torimoto, Chem. Commun., 2016, 52, 12241.

66 H. Wender, L. F. de Oliveira, P. Migowski, A. F. Feil, E. Lissner, M. H. G. Prechtl, S. R. Teixeira and J. Dupont, J. Phys. Chem. C, 2010, 114, 11764.

67 T. Suzuki, K. Okazaki, T. Kiyama, S. Kuwabata and T. Torimoto, Electrochemistry, 2009, 77, 636.

68 M. M. Alvarez, J. T. Khoury, T. G. Schaaff, M. N. Shafigullin, I. Vezmar and R. L. Whetten, J. Phys. Chem. B, 1997, 101, 3706.

69 J. H. Hodak, A. Henglein and G. V. Hartland, J. Chem. Phys., 2000, 112, 5942.

70 V. Subramanian, E. E. Wolf and P. V. Kamat, J. Am. Chem. Soc., 2004, 126, 4943.

71 J. Li, Y. Ye, L. Ye, F. Su, Z. Ma, J. Huang, H. Xie, D. E. Doronkin, A. Zimina, J.-D. Grunwaldt and Y. Zhou, J. Mater. Chem. A, 2019, 7, 2821.

72 Y. H. Jang, Y. J. Jang, S. Kim, L. N. Quan, K. Chung and D. H. Kim, Chem. Rev., 2016, 116, 14982. 